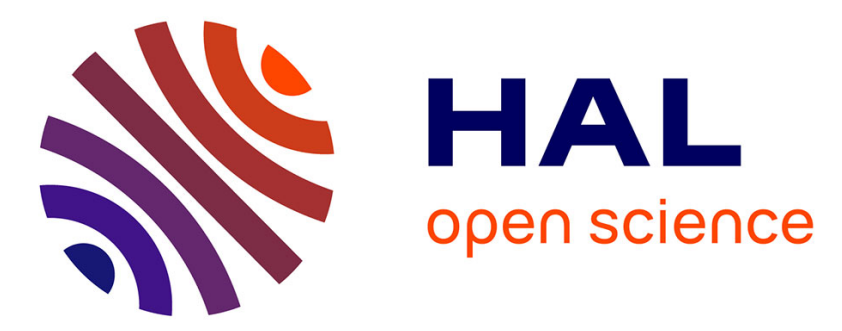

\title{
Application of a simplifying model to the breakage of different materials in an air jet mill
}

\author{
Olivier Lecoq, Alain Chamayou, John A. Dodds, P. Guigon
}

\section{To cite this version:}

Olivier Lecoq, Alain Chamayou, John A. Dodds, P. Guigon. Application of a simplifying model to the breakage of different materials in an air jet mill. INTERNATIONAL JOURNAL OF MINERAL PROCESSING, 2011, 99 (1-4), p.11-16. 10.1016/j.minpro.2012.04.004 . hal-01667188

\section{HAL Id: hal-01667188 https://hal.science/hal-01667188}

Submitted on 6 Nov 2019

HAL is a multi-disciplinary open access archive for the deposit and dissemination of scientific research documents, whether they are published or not. The documents may come from teaching and research institutions in France or abroad, or from public or private research centers.
L'archive ouverte pluridisciplinaire HAL, est destinée au dépôt et à la diffusion de documents scientifiques de niveau recherche, publiés ou non, émanant des établissements d'enseignement et de recherche français ou étrangers, des laboratoires publics ou privés. 


\title{
Application of a simplifying model to the breakage of different materials in an air jet mill ${ }^{\text {is }}$
}

\author{
O. Lecoq ${ }^{\text {a,* }}$, A. Chamayou ${ }^{\text {a }}$, J.A. Dodds ${ }^{\text {a }}$, P. Guigon ${ }^{\text {b }}$ \\ a Ecole des Mines d'Albi, Laboratoire RAPSODEE. 81000 Albi, France \\ b Université de Technologie de Compiègne, Département de Génie des Procédés Industriels, BP 20529-60205 Compiègne cedex, France
}

Keywords:

Fragmentation

Model

Impact

Air-jet mill

Powder

\begin{abstract}
A B S T R A C T
This paper describes the application of a unifying 'master curve' model for single impact size reduction in an air jet mill. Based on a dimensional analysis and a modified fracture mechanical theory, it enables to relate the weight percentage of broken particles under sieve cut size to the mean sieve cut size of the studied material, the net kinetic energy provided to the material, the number of impacts and a global parameter $f_{\text {Mat }}$. Altogether 11 sieve cuts of different materials are impacted in an experimental air jet mill. Minimum breakage energies are derived and are shown to vary with a power function of the sieve cut size. The simplifying model is then successfully applied and enables to derive the fMat. parameters. In our situation, the experimental data do not show a direct relationship between fMat. and the minimum breakage energy and sieve cut size for all the materials.
\end{abstract}

\section{Introduction}

Comminution is a very important unit operation in the industrial world, but so far it is still lacking of fundamental understanding of all the phenomena involved. Its complexity, linked to the size reduction process, to the material properties and the interactions between them (Schönert, 1995) can nevertheless be tackled with the help of different approaches (Salman et al., 2007), for example the energy laws, mechanical physics, mass balance with specific rate of breakage or selection function and breakage distribution function, dimensional analysis, simulation and modelling, and residence time distribution. One could argue that they are not reflecting the reality, they are even modifying by simplifying the reality, but "in science it is always necessary to abstract from the complexity of the real world, and in its place to substitute a more or less idealised situation that is more amenable to analysis" (Levenspiel, 2002). Eventually, it is important to consider them if they give us tools for control, design or prediction of the particle size distribution. Even sometimes they help us in understanding some physical grinding phenomena (e.g. Menacho, 1986). In this paper, we want to illustrate the use of a breakage by the impact model developed by Vogel and Peukert (2003) with breakage single impact results carried out in an air-jet mill obtained by Lecoq et al. (2003). We will discuss on

\footnotetext{
is A publishers' error resulted in this article appearing in the wrong issue. The article is reprinted here for the reader's convenience and for the continuity of the special issue. For citation purposes, please use the original publication details; International Journal of Mineral Processing, 99(1-4), pp. 11-16. **DOI of original item: doi:10.1016/j.minpro.2011.01.003. * Corresponding author. Tel.: +33563493069.

E-mail address: lecoq@enstimac.fr (O. Lecoq).
}

its application and validity to several different materials and compare it to previous grindability approach. Previous papers already used the model, for example with pharmaceutical powders (Meier et al., 2008).

\section{Presentation of the model}

The model used and developed by Vogel and Peukert (2003) is based on a generalising dimensional analysis (Rumpf, 1973) and a modified fracture mechanical theory (Weichert, 1992). More information on its derivation can be found in Vogel and Peukert (2003).

The basics are as follows. For a set of geometrically similar and physically identical particles, the breakage pattern should be similar if the elastically stored strain energy per unit volume multiplied by the initial particle size is constant. Relations are then derived including several material physical properties: Young's modulus, Poisson ratio, initial crack length or flaw size, and crack extension energy per unit of created surface energy. Then Weibull statistics and the Hertz theory for impacting elastic spheres are added. In this situation the Weibull coefficient is set to 4 . Finally, theoretical justification and simplification provide a very simple relation to characterise the breakage after $k$ impacts of a cut sieve of one given material of initial size $x$ :

$S=1-\exp \left\{-f_{\text {Mat. }} \cdot x \cdot k \cdot \Delta W\right\}$

with

\begin{tabular}{lll}
\hline$S$ & $\begin{array}{l}\text { the breakage probability function or selection } \\
\text { function, approximated here by the weight } \\
\text { percentage of broken particle under sieve cut size }\end{array}$ & \\
\hline
\end{tabular}




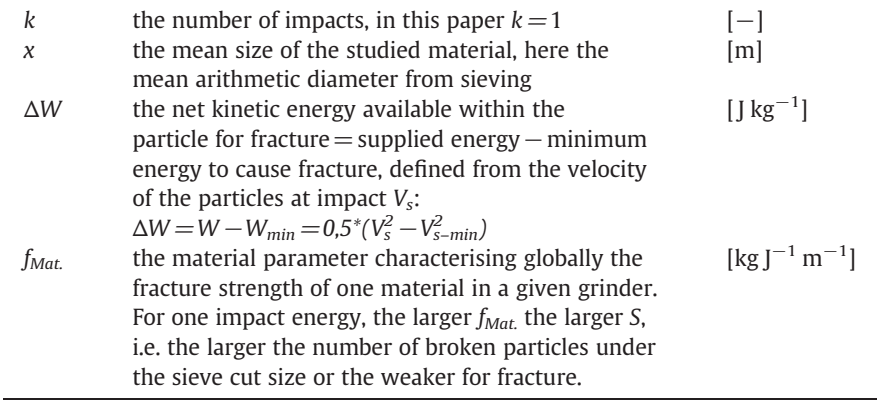

The interesting part in the theoretical development is that the initial formulation of Rumpf (1973) is simplified in the way that only one parameter, $f_{\text {Mat. }}$, is actually characterising the behaviour of the material in the grinder. Two other advantages of the formulation appear clearly:

- the situation of single and repeated impacts can be considered with the help of the $k$ parameter. But the strong hypothesis is that the material behaves identically for any impact, i.e. is not influenced by its previous history,

- if one plots $S$ vs. $f_{\text {Mat. }} \cdot x \cdot k \cdot \Delta W$ a master-curve is highlighted: no matter what the material, the grinder and the operating conditions are, the comminution phenomenon is reduced in an increasing exponential curve.

This model is for sure oversimplifying the improbable pure brittle failure reality, but is attractive because, it allows one to describe a very complex phenomenon with two parameters: one characterising the material and another characterising the supplied kinetic energy by the grinder to the particles. Mechanical properties are progressively introduced into the model, e.g. in Meier et al. (2009).

\section{Experimental methods for the impact tests}

\subsection{Air-jet mill and methodology}

The used apparatus (see Fig. 1) is designed to study the fracture of particles accelerated in a jet of air and impacting on a silicon carbide target (Lecoq et al., 2003). The impact velocity is obtained from optical fibre system described in Mebtoul et al. (1996). The experiments are performed in very dilute regime in order to minimise particle-particle interactions in the jet, in the nozzle and on impact. After impact, the debris are recovered and analysed by sieving.

The followed methodology allows one to derive the relationships between the particle size distributions and the impact velocity or the specific kinetic energy. The attrition threshold $W_{\min }$ is determined by extrapolation of these curves to final diameter equal to initial diameter (Lecoq et al., 2003).

\subsection{Tested solids}

Three different materials have been tested: glass beads (cuts 70 $110 \mu \mathrm{m}, 90-150 \mu \mathrm{m}, 300-400 \mu \mathrm{m}, 425-850 \mu \mathrm{m}), \mathrm{Al}(\mathrm{OH})_{3}$ (cuts 32 $45 \mu \mathrm{m}, 45-63 \mu \mathrm{m}, 63-90 \mu \mathrm{m}, 90-125 \mu \mathrm{m}$ ) and $\mathrm{NaCl}$ (cuts 200-315 $\mu \mathrm{m}$, $315-500 \mu \mathrm{m}, 500-800 \mu \mathrm{m}$ ). More information can be found in Lecoq et al. (2003).

\section{Results}

\subsection{Initial results}

The impact test results are shown in Fig. 2 in a traditional way: the weight percentage of broken particle under sieve cut size (e.g. for the cut $70-110 \mu \mathrm{m}$, the \% under $70 \mu \mathrm{m}$ ), versus the net kinetic energy. It can be seen that the larger the provided energy, the larger the number of broken particles under the sieve cut. Fig. 2 also reveals that the 70 $110 \mu \mathrm{m}$ glass sieve cut is the strongest impacted powder, whereas the $500-800 \mu \mathrm{m} \mathrm{NaCl}$ is the weakest.

\subsection{Direct application of the model}

From the raw data from Fig. 2 it is possible to derive $f_{\text {Mat. }}$ parameters (cf Table 1) which enables to draw the master curve in Fig. 3. Visually speaking, the highlighted master curve shows a good validation of the applied model. All the data fits the increasing exponential shaped curve validating the initial supposed similar breakage pattern and the influence of impact energy and initial particle size.

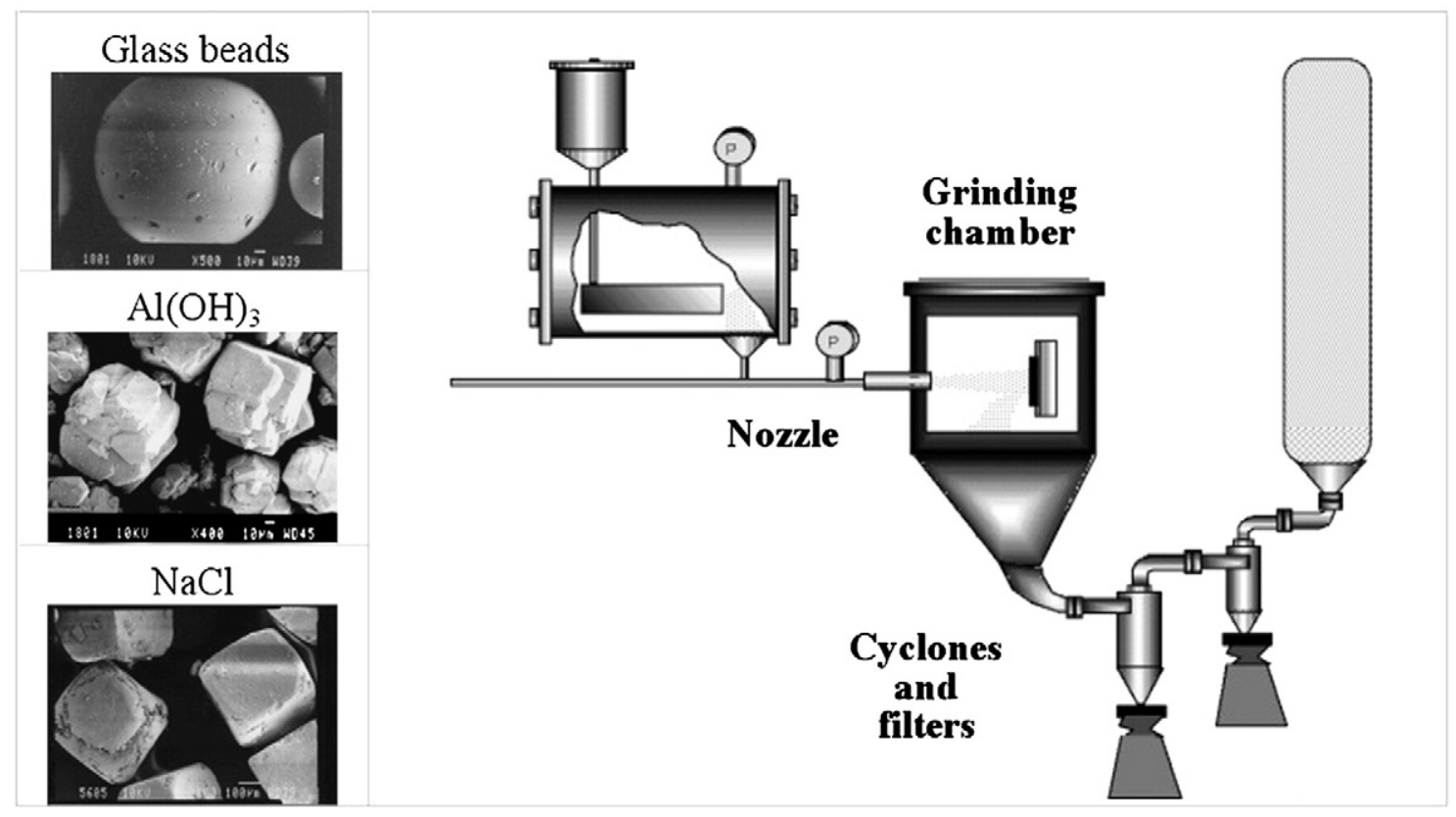

Fig. 1. Experimental single jet apparatus (Lecoq et al. 2003). 


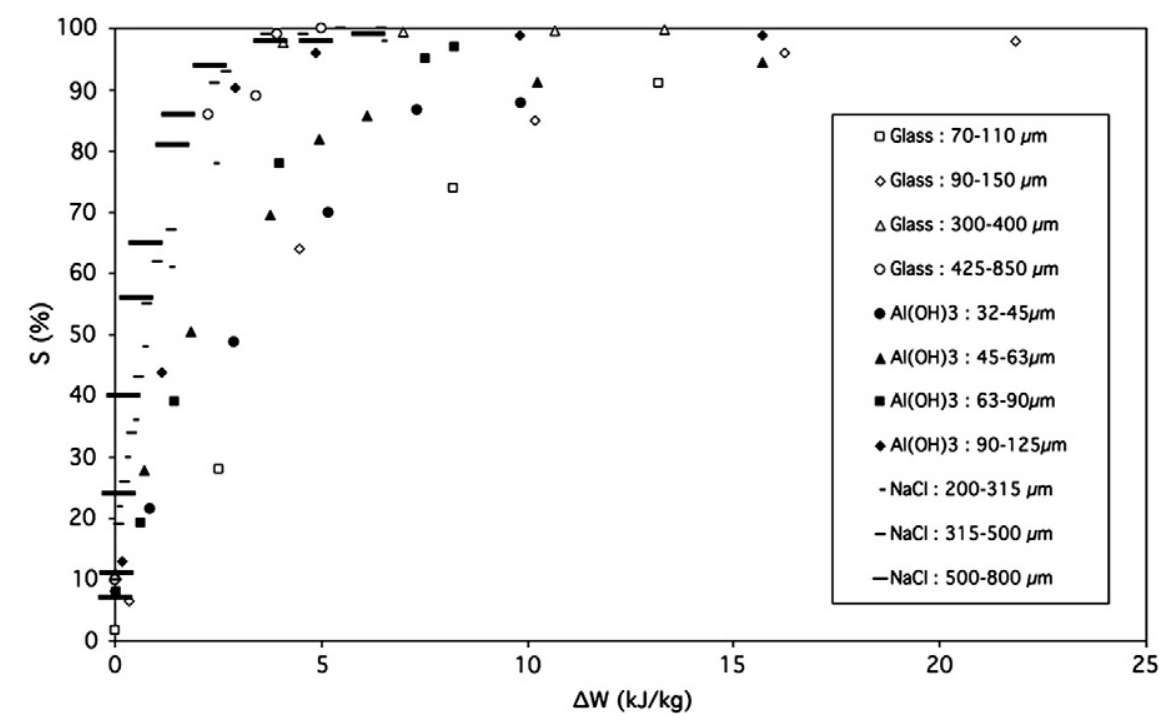

Fig. 2. Impact results with $S$ vs. net energy $\Delta W$.

No matter what the material is, the behaviour seems simplified into an apparently common normalised behaviour. For a given material and for the particle size range investigated the material function should be "constant". But more precisely, according to the material, the relative standard deviation varies from a few percent (for $\left.\mathrm{Al}(\mathrm{OH})_{3}\right)$ up to $16 \%$ (for glass beads).

\section{Discussion}

\subsection{Material function $f_{\text {Mat. }}$}

The mean value of $f_{\text {Mat. }}$ for the used glass beads (1.9) is within the range of the glass sphere data (0.95) from Vogel and Peukert (2003), considering that the two materials are different types of glass. Finally, the relative variations of the derived parameters $f_{\text {Mat. }}$ go from a few percent to $38 \%$.

\subsection{Attrition threshold $W_{\min }$}

The similarity of the breakage pattern implies the product $x W_{\min }$ to be constant. Table 1 gives the statistical details of the calculations, revealing that the relative deviations vary between $25 \%$ and $50 \%$. This shows the quantitative limit of the model with the obtained data.

To go further, it was also decided to test statistically our data with the Eq. (2) linking $W_{\min }(\mathrm{kJ} / \mathrm{kg})$ and $x(\mu \mathrm{m})$. Compared to the Hertzian theory (Timoshenko and Goodier, 1987; Kanda et al., 1989) the coefficient $b$ should be equal to $10 / 3$ or more precisely with the Weibul coefficient $m$ equal to $5 / m$ (Yashima et al., 1987).

$W_{\text {min }}=\frac{a}{x^{b}}$

Fig. 4 shows the relationship between the attrition threshold $W_{\min }$ and the sieve cut size $x$ for the three materials investigated. As expected it is all the more difficult to break particles as their size decreases. All the three determined straight lines are almost parallel and more strikingly the $\mathrm{Al}(\mathrm{OH})_{3}$ and $\mathrm{NaCl}$ points seem to be on the same line. Table 2 gives the determined data $a$ and $b$ with the corresponding correlation coefficient, which are quite acceptable. The power dependence is always between 1 and 2 but very far from the Hertzian theory (3.3). If we compare with the literature, Weichert (1990) found a power of 1.1, but of course with a different type of glass.

Table 1

Material characteristics for the three studied powders. ( $f_{\text {Mat }}, x, W_{\min }, V_{\text {so }}$ defined in Eq. (1); for $p$ see Section 5.4).

\begin{tabular}{|c|c|c|c|c|c|c|}
\hline Glass cuts $(\mu \mathrm{m})$ & Sieve size $x(\mu \mathrm{m})$ & $f_{\text {Mat. }}\left(\mathrm{kg} \mathrm{J}^{-1} \mathrm{~m}^{-1}\right)$ & $x \cdot W_{\min }\left(\mathrm{m} \mathrm{J} \mathrm{kg}^{-1}\right)$ & $V_{s o}\left(\mathrm{~m} \mathrm{~s}^{-1}\right)$ & $W_{\text {min }}\left(\mathrm{kJ} \mathrm{kg}^{-1}\right)$ & $p\left(\mathrm{~m}^{2} \mathrm{~kJ}^{-1}\right)$ \\
\hline $425-850$ & 555 & 1.7 & 0.11 & 20 & 0.20 & 2.0 \\
\hline $300-400$ & 351 & 2.3 & 0.16 & 30 & 0.45 & 2.1 \\
\hline $90-150$ & 129 & 1.4 & 0.13 & 46 & 1.06 & 2.7 \\
\hline \multirow[t]{2}{*}{$70-110$} & 103 & 1.7 & 0.33 & 80 & 3.20 & 2.8 \\
\hline & & $1.8 \pm 0.3(16 \%)$ & $0.18 \pm 0.09(39 \%)$ & & & \\
\hline $\mathrm{Al}(\mathrm{OH})_{3}$ Cuts $(\mu \mathrm{m})$ & Sieve size $x(\mu \mathrm{m})$ & $f_{\text {Mat. }}\left(\mathrm{kg} \mathrm{J}^{-1} \mathrm{~m}^{-1}\right)$ & $x \cdot W_{\min }\left(\mathrm{m} \mathrm{J} \mathrm{kg}^{-1}\right)$ & $V_{s o}\left(\mathrm{~m} \mathrm{~s}^{-1}\right)$ & $W \min \left(\mathrm{kJ} \mathrm{kg}^{-1}\right)$ & $p\left(\mathrm{~m}^{2} \mathrm{~kJ}^{-1}\right)$ \\
\hline $90-125$ & 103 & 5.0 & 0.03 & 26 & 0.33 & 7.9 \\
\hline $63-90$ & 83 & 4.9 & 0.04 & 33 & 0.55 & 8.2 \\
\hline $45-63$ & 54 & 5.1 & 0.06 & 48 & 1.15 & 9.5 \\
\hline \multirow[t]{2}{*}{$32-45$} & 43 & 5.5 & 0.06 & 54 & 1.45 & 14.3 \\
\hline & & $5.1 \pm 0.2(4 \%)$ & $0.05 \pm 0.01(25 \%)$ & & & \\
\hline $\mathrm{NaCl}$ Cuts $(\mu \mathrm{m})$ & Sieve size $x(\mu \mathrm{m})$ & $f_{\text {Mat. }}\left(\mathrm{kg} \mathrm{J}^{-1} \mathrm{~m}^{-1}\right)$ & $x \cdot W_{\min }\left(\mathrm{m} \mathrm{J} \mathrm{kg}^{-1}\right)$ & $V_{s o}\left(\mathrm{~m} \cdot \mathrm{s}^{-1}\right)$ & $W_{\min }\left(\mathrm{kJ} \mathrm{kg} .^{-1}\right)$ & $p\left(\mathrm{~m}^{2} \mathrm{~kJ}^{-1}\right)$ \\
\hline $500-800$ & 602 & 1.9 & 0.02 & 8 & 0.03 & 3.0 \\
\hline $315-500$ & 400 & 2.5 & 0.02 & 10 & 0.05 & 5.5 \\
\hline \multirow[t]{2}{*}{$200-315$} & 245 & 2.5 & 0.03 & 16 & 0.13 & 6.0 \\
\hline & & $2.3 \pm 0.3(13 \%)$ & $0.02 \pm 0.01(50 \%)$ & & & \\
\hline
\end{tabular}




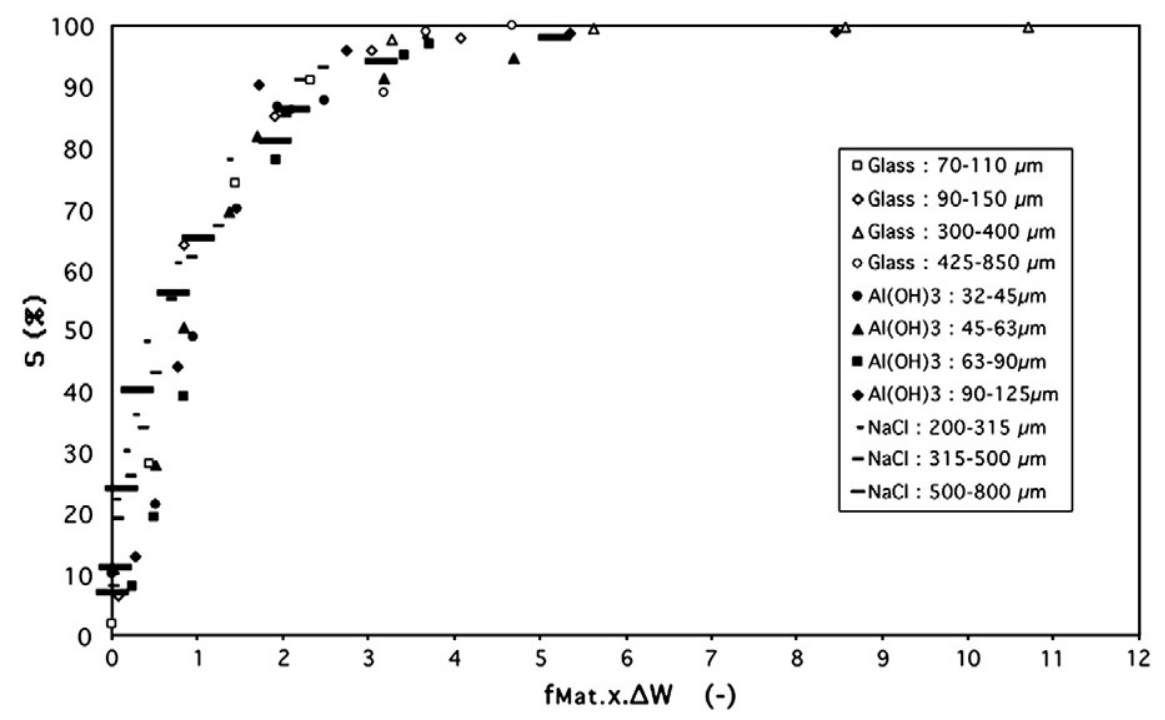

Fig. 3. Master curve with $S$ vs. dimensionless parameter $f_{\text {Mat. }} \cdot x \cdot \Delta W$.

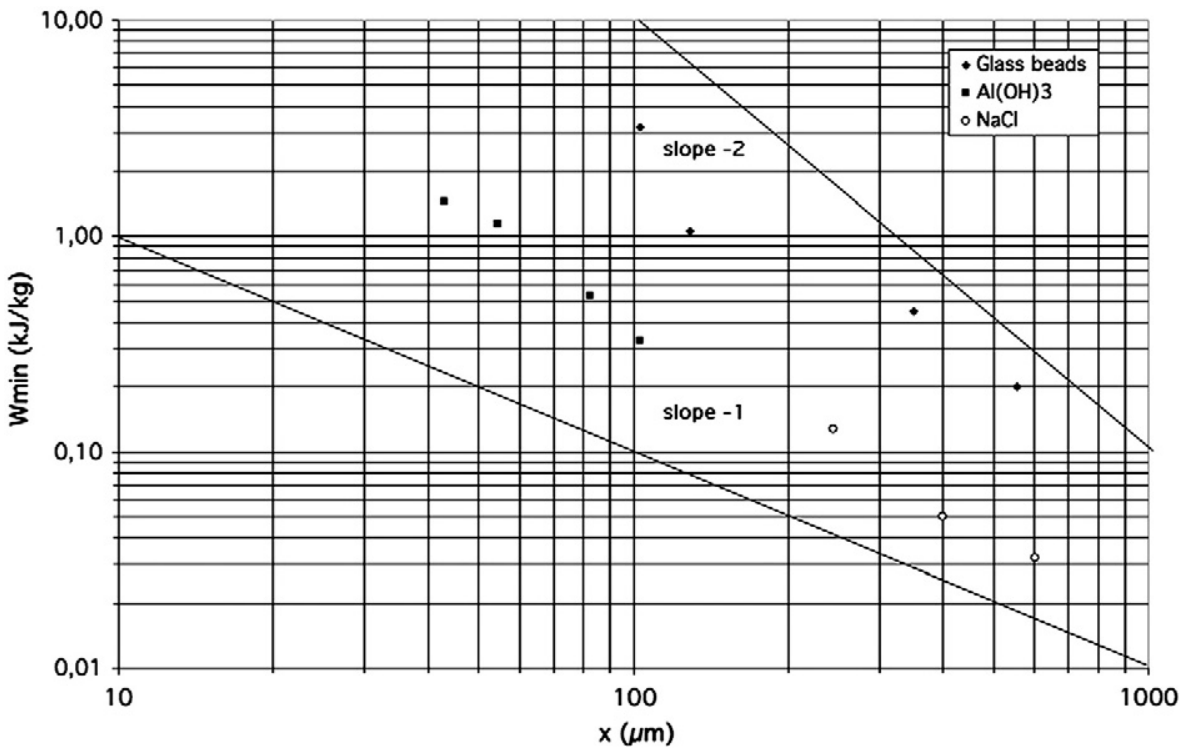

Fig. 4. Dependence between attrition threshold $W_{\min }$ and the sieve cut size $x$.

\subsection{Are $f_{\text {Mat. }}$ and the attrition threshold $W_{\min }$ linked ?}

Peukert (2002) has shown a direct relationship between $f_{\text {Mat. }}$ and $x$ $W_{\min }$ according to relation (3) for different materials, ranging from polymers to limestone or glass, with size between $95 \mu \mathrm{m}$ and $8 \mathrm{~mm}$. Two zones are distinguished: 'brittle' for high $f_{\text {Mat. }}$ and 'visco-elastic' for low $f_{\text {Mat. }}$. In our situation our materials are always brittle with $f_{\text {Mat. }}$ larger than 1.

$f_{\text {Mat. }}=0.22 \cdot\left(x \cdot W_{\min }\right)^{-0.63}$

In the situation depicted in Fig. 5, considering only $\mathrm{Al}(\mathrm{OH})_{3}$ and glass, a power dependence would be possible, but the detected dependence would be $f_{\text {Mat. }} \propto\left(x \cdot W_{\text {min }}\right)^{-0.9}$ which is about $30 \%$ away from the one in relation (3). If we consider only $\mathrm{NaCl}$, the data fit satisfactorily with Eq. (3). In conclusion, there is no common power relation for all the studied materials. More experimental work is definitely necessary to go further in the analysis.

\subsection{On the meaning of $f_{\text {Mat. }}$}

As previously said $f_{\text {Mat. }}$ characterises globally the grindability of the powder in the grinder: it must include the material properties. Other grindability parameters exist in the literature, for this paper we decided to use the one obtained in the same apparatus and described by Lecoq et al. (2003), i.e. $p$ which represents the amount of created surface per increase in impact energy (cf Table 1 ). Contrary to $f_{\text {Mat. }}$ it depends on the size of the material. If we compare them directly for the three studied materials, the $f_{\text {Mat }}$ and the $p$ data lead to the same grindability order: glass is the "stronger" material and $\mathrm{Al}(\mathrm{OH})_{3}$ is the

Table 2

Correlation parameters corresponding to Eq. (2) (for $W_{\min }$ in $\mathrm{kJ} / \mathrm{kg}$ and $x$ in $\mu \mathrm{m}$ ).

\begin{tabular}{llll}
\hline Material & $a$ & $b$ & $\mathrm{R}^{2}$ \\
\hline $\mathrm{Glass}$ & 1635 & 1.4 & 0.92 \\
$\mathrm{Al}(\mathrm{OH})_{3}$ & 987 & 1.7 & 0.99 \\
$\mathrm{NaCl}$ & 626 & 1.6 & 0.98
\end{tabular}




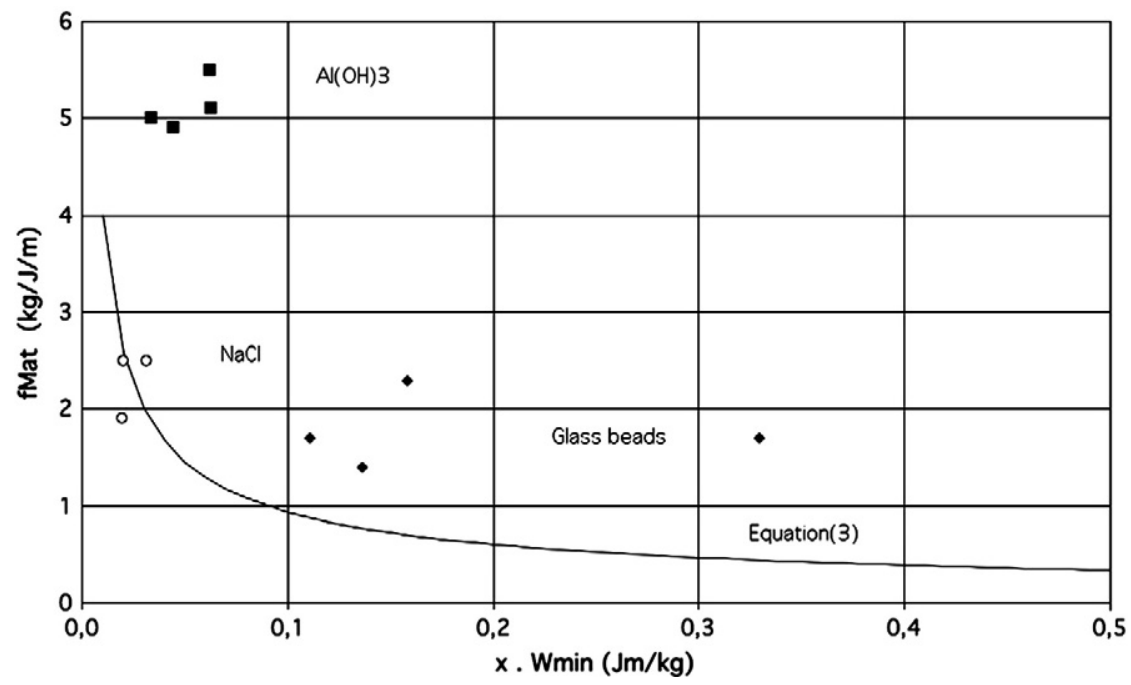

Fig. 5. Dependence between the material parameter $f_{\text {Mat. }}$ and $x \cdot W_{\text {min }}$.

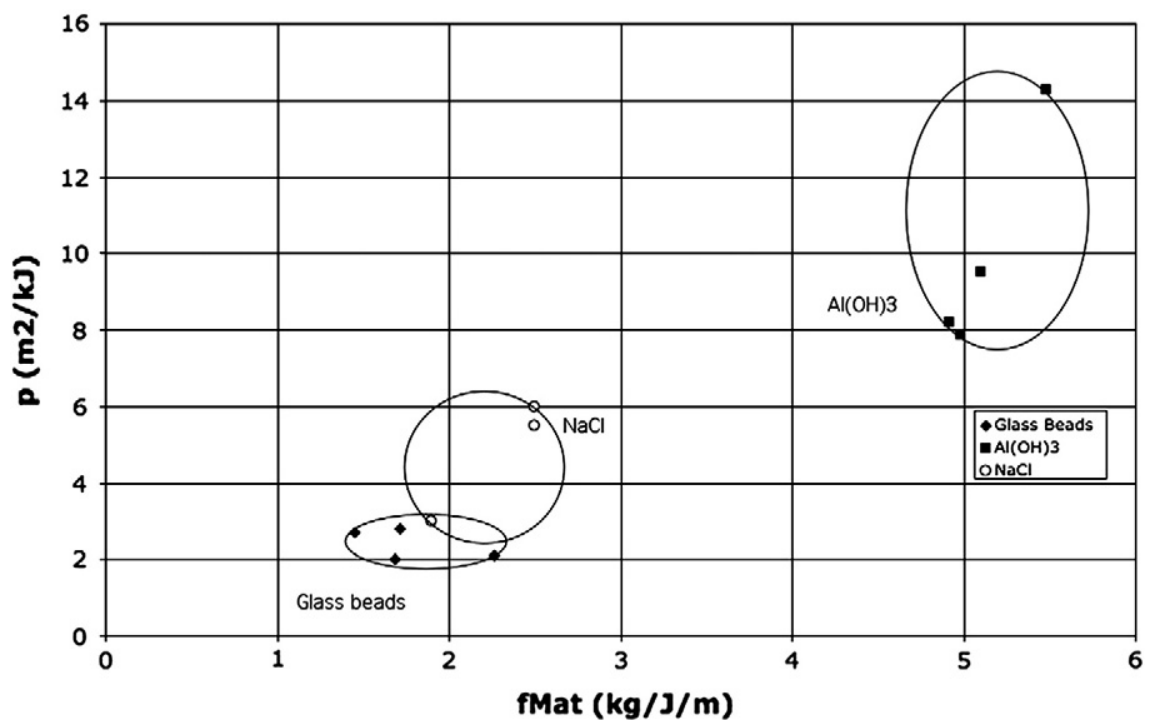

Fig. 6. Direct comparison of the two grindability parameters.

"weaker" material (Fig. 6). But the meanings are different: for $p$, the larger the data, the more surface is created per provided energy. For $f_{\text {Mat. }}$ the larger the data, the more broken particles under the sieve cut.

\section{Conclusions}

The proposed literature model developed by Vogel and Peukert (2003) applies here successfully on single impact results carried out in an air-jet mill. A universal master curve is highlighted. The two parameters of the model $f_{\text {Mat. }}$ and $W_{\text {min }}$ can be easily derived, even if there is a certain standard deviation according to the number of experimental data: the $f_{\text {Mat. }}$ parameter is not strictly constant with the sieve cut of the studied material. Besides contrarily to what the authors have observed, no direct relation between these two parameters have been found. The interesting part in this simplifying approach is that once the two parameters are known, the comminution behaviour of the powder should be perfectly known. But one must bear in mind that in the approach the $S$ function is determined from sieving. The $f_{\text {Mat }}$. value is then determined with this chosen granulometric method. It is expected to derive another value if laser granulometry is used instead.

In this context, the attrition threshold has been found to be inversely proportional to the size of the impacted particle to a power between 1 and 2. This is to be related to the hypothesis from Rumpf (1973): the breakage pattern being similar if the elastically stored strain energy per unit volume multiplied by the initial particle size is constant.

Finally, a comparison between $f_{\text {Mat. }}$ and the grindability parameter $p$ developed by Lecoq et al. (2003) shows a possible correlation even if they do not have the same meaning: the former is global and encompasses the material properties, the latter defines an increase of specific surface per provided energy in the grinder. In future work the material parameter $f_{\text {Mat }}$. will be investigated more precisely in order to show its variation with the material mechanical properties and the number of impacts.

\section{References}

Kanda, Y., Abe, Y., Hosoya, T., Honma, T., 1989. A consideration of ultrafine grinding based on experimental result of single particle crushing. Powder Technology 58, 137-143. 
Lecoq, O., Chouteau, N., Mebtoul, M., Large, J.-F., Guigon, P., 2003. Fragmentation by high velocity impact on a target: a material grindability test. Powder Technology 133 , 113-124.

Levenspiel, O., 2002. Modelling in chemical engineering. Chemical Engineering Science 57, 4691-4696.

Mebtoul, M., Large, J.F., Guigon, P., 1996. High velocity impact of particles on a target. An experimental study. International Journal of Mineral Processing 44-45, 77-91.

Meier, M., et al., 2008. Characterisation of the grinding behaviour in a single particle impact device: studies on pharmaceutical powders. European Journal of Pharmaceutical Sciences 31, 45-55.

Meier, M., et al., 2009. Influence of mechanical properties on impact fracture: prediction of the milling behaviour of pharmaceutical powders by nanoindentation. Powder Technology 188, 301-313.

Menacho, J.M., 1986. Some solutions for the kinetics of combined fracture and abrasion breakage. Powder Technology 49, 87-96.

Peukert, W., 2002. Material properties in fine grinding. 10th European Symposium on Comminution. Heidelberg, Germany.
Rumpf, $\mathrm{H}$., 1973. Physical aspects of comminution and new formulation of a law of comminution. Powder Technology 7, 145-159.

Salman, A.D., Ghadiri, M., Hounslow, M.J. (Eds.), 2007. Particle Breakage. Elsevier.

Schönert, K., 1995. Comminution from theory to practice: XIX International Mineral Processing Congress, vol. 1, pp. 7-14. October 22-27.

Timoshenko, S.P., Goodier, J.N., 1987. Theory of Elasticity, 3 rd edition. McGraw Hill.

Vogel, L., Peukert, W., 2003. Breakage behaviour of different materials-construction of a mastercurve for the breakage probability. Powder Technology 129, 101-110.

Weichert, R., 1990. Fracture physics in comminution. Preprints 7th European Symposium on Comminution: EFCE Publication Series 85, pp. 3-20. Ljubljana.

Weichert, R., 1992. Application of defect statistics and fracture mechanics for describing comminution processes. Zement-Kalk-Gips 3, 51-57.

Yashima, S., Kanda, Y., Sano, S., 1987. Relationships between particle size and fracture energy or impact velocity required to fracture as estimated from single particle crushing. Powder Technology 51, 227-282. 